\title{
Análise ergonômica do trabalho em atividades desenvolvidas com uma roçadora manual motorizada
}

\author{
Work ergonomic assessment on the activities developed with brush cutter mower
}

\author{
Airton dos Santos Alonço ${ }^{1}$ Camila Ardais Medeiros ${ }^{2}$ Fabrício Ardais Medeiros $^{3}$ \\ Valmir Werner ${ }^{3}$
}

\section{- NOTA -}

\section{RESUMO}

Este trabalho teve por objetivo avaliar a operação de roçadoras manuais motorizadas, visto que estas cada vez mais são usadas nas operações de limpeza no meio rural e urbano. Além disso, procurou-se demonstrar, por meio da análise realizada a campo, que muitas das ações e métodos utilizados para desenvolver o trabalho contrapõem-se às normas regulamentadoras de segurança e saúde no trabalho. Alerta-se os trabalhadores e empregadores sobre os riscos de acidentes de trabalho e/ou de doenças ocupacionais e sugerese maneiras mais adequadas para a execução destas tarefas.

Palavras-chave: engenharia agrícola, máquinas agrícolas, ergonomia.

\section{ABSTRACT}

This research work was aimed at evaluating the operation with a brush cutter mower, because they are more and more used in rural and urban environment. Besides, it tried to demonstrate - through the field operational analysis that many of the operation procedures are non-conforming to operational human health and safety regulation norms. This work alerts workers and employers on the work hazards and/or occupational diseases, suggesting more appropriate ways to execute these tasks.

Key words: agricultural engineering, agricultural machines, ergonomics.

A utilização de máquinas manuais, tais como roçadoras, moto-serras e pulverizadores, tem assumido um importante papel no manejo de áreas agricultáveis. Para operar com este tipo de equipamento, deve-se, no entanto, levar em consideração parâmetros ligados à máquina como, por exemplo, funcionamento, conformação e adaptabilidade às diferentes condições de operação e trabalho. Contudo, é importante considerar a interação homem-máquina como, por exemplo, a temperatura de trabalho, o intervalo de tempo de utilização ininterrupta e a utilização de dispositivos de segurança, devendo-se sempre considerar o operador como principal elemento do sistema (ALONÇO, 2004).

A análise desses parâmetros se faz necessária para evitar riscos de acidentes de trabalho que poderão ocorrer em função de "não conformidades" encontradas na máquina e pela falta do uso do equipamento de proteção individual (EPI) pelos operadores.

Para auxiliar o levantamento e interpretação dos dados, foram utilizados conceitos básicos de ergonomia, tais como a Norma Regulamentadora sobre equipamentos de proteção individual - NR 6 (1992), a Norma Regulamentadora sobre atividades e operações insalubres - NR 15 (1990) e a Norma Regulamentadora sobre segurança e saúde no trabalho na agricultura, pecuária, silvicultura, exploração florestal e aqüicultura -NR31 (2005).

A NR 6 (1992), considera que "EPI é todo o dispositivo ou produto, de uso individual utilizado pelo trabalhador destinado à proteção de riscos suscetíveis de ameaçar a segurança do trabalhador”. Desta forma, o empregador é obrigado a fornecer EPI aos

\footnotetext{
${ }^{1}$ Departamento de Engenharia Rural, Centro de Ciências Rurais (CCR), Universidade Federal de Santa Maria (UFSM), 97105-900, Santa Maria, RS, Brasil. E-mail: alonço@ccr.ufsm.br. Autor para correspondência.

${ }^{2}$ Programa de Pós-graduação em Engenharia de Produção, UFSM, Santa Maria, RS, Brasil.

${ }^{3}$ Programa de Pós-graduação em Engenharia Agrícola, UFSM, Santa Maria, RS, Brasil.
} 
empregados gratuitamente e em perfeito estado de uso, e estes devem cumprir as determinações do empregador sobre o uso adequado. Para o trabalho de roçagem, portanto, é indispensável o uso do protetor auditivo, de óculos, de calça para proteger o indivíduo de agentes cortantes e escoriantes e de luvas para proteção das mãos contra vibrações e agentes cortantes. Estas mesmas exigências também se fazem presentes na NR 31(2005).

A melhoria das condições de trabalho é feita pela análise das condições físicas de trabalho, como temperatura, ruídos e vibrações. O desconforto térmico e as vibrações são os principais fatores que afetam o comportamento normal das pessoas, visto que existe uma taxa aceitável de exposição tolerável pelo ser humano (ALONÇO, 2004).

Ao tomar o ruído como parâmetro (NR 15, 1990), observa-se que a permanência do operador durante um período de oito horas diárias de trabalho só será possível até um grau de exposição de $85 \mathrm{~dB}$ (A). Níveis de ruído acima desse valor começam a afetar psicologicamente o trabalhador, causando, em muitas situações, lesões auditivas irreversíveis, levando-o à surdez, além de afetar a execução de tarefas que exijam atenção, velocidade ou precisão de movimentos (VENTUROLI, 2003).

Conforme consta na NR 31 (2005), cabe ao empregador ou equiparado "realizar avaliações dos riscos para a segurança e saúde dos trabalhadores e, com base nos resultados, adotar medidas de prevenção e proteção para garantir que todas as atividades, lugares de trabalho, máquinas, equipamentos, ferramentas e processos produtivos sejam seguros e em conformidade com as normas de segurança e saúde”. O empregador deve adotar princípios ergonômicos para melhorar as condições de conforto e segurança no trabalho para seus funcionários, sendo que as atividades que forem realizadas necessariamente em pé ou que exijam sobrecarga muscular deverão ter garantidas pausas para descanso.

Assim sendo, o trabalho teve por objetivo analisar ergonomicamente atividades realizadas com uma roçadora manual motorizada, tendo como base aspectos determinados nas normas citadas.

O trabalho foi realizado no município de Santa Maria/RS, analisando as atividades realizadas pelos operadores de uma empresa de prestação de serviços, na operação de uma roçadora manual motorizada, por meio de observações e questionamentos com os operadores da máquina.

O trabalho constituiu-se na observação de “conformidades” e "não conformidades” com o que é determinado na NR 15(1990), na NR 6 (1992) e na NR 31
(2005), durante a realização de atividades de corte de grama, arbustos e capoeiras, nas quais foi utilizada uma roçadora da marca Stihl, modelo FS 160, potência no motor de 1,4kW, rotação máxima sem ferramenta de corte de $12.000 \mathrm{rpm}$, cilindrada de $29,8 \mathrm{~cm}^{3}$, rotação em marcha lenta de 2.800rpm, tanque de combustível com capacidade de 0,58 litros e 7,4 quilogramas de peso total.

Após realizadas as observações de campo e feitos os registros fotográficos e sonoros, estes foram confrontados com o conteúdo das Normas Regulamentadoras.

Segundo ALONÇO (2004), “toda peça móvel que apresente risco ao operador, como por exemplo, engrenagens, volantes, excêntricos e outros, deverão ser projetados embutidos ou protegidos”. Sob este aspecto, a máquina analisada, por se tratar de um sistema que possui um mecanismo de rotação para corte, com rotação máxima de $12.000 \mathrm{rpm}$, necessita, obrigatoriamente, possuir sistema de proteção para evitar que ocorram acidentes, fato este corroborado pela NR 31 (2005).

Porém, como pode ser observado na Figura 1a, a estrutura protetora não é utilizada no processo de roçagem pelos operários, não pelo fato de não existir, mas sim por ser um dispositivo retirado pelos próprios operários, o que, segundo seu relato, deve-se à ocorrência de constantes embuchamentos durante a operação. Assim sendo, ou o equipamento é mal projetado (o que seria um aspecto de projeto a ser solucionado pela indústria), ou é erroneamente operado (indicando a necessidade de capacitação dos operadores).

$\mathrm{Na}$ figura $1 \mathrm{~b}$, pode ser visualizado o trabalhador em processo de roçagem, com uma correta postura do corpo, de forma que os braços e pernas desenvolvem movimentos em detrimento do uso da coluna vertebral, o que é uma "conformidade" ergonômica. Outra "conformidade” encontrada foi em relação ao sistema de ignição da máquina. Conforme pode ser observado na figura 1c, há uma correta postura para o seu funcionamento. Ou seja, o trabalhador, num posicionamento ereto, com a mão direita dá a partida no motor, enquanto que o botão de acionamento e o acelerador, localizados na empunhadura direita, são acionados com a mão esquerda (Figura 1d).

A presença de pedregulhos, ciscos, tampas de garrafa e outros são constantes nos gramados. No processo de roçagem, o risco de algum destes materiais atingir o operador em partes sensíveis do seu corpo é iminente. Por isso, deve-se dar também uma atenção especial aos óculos de proteção do operador e às luvas, 


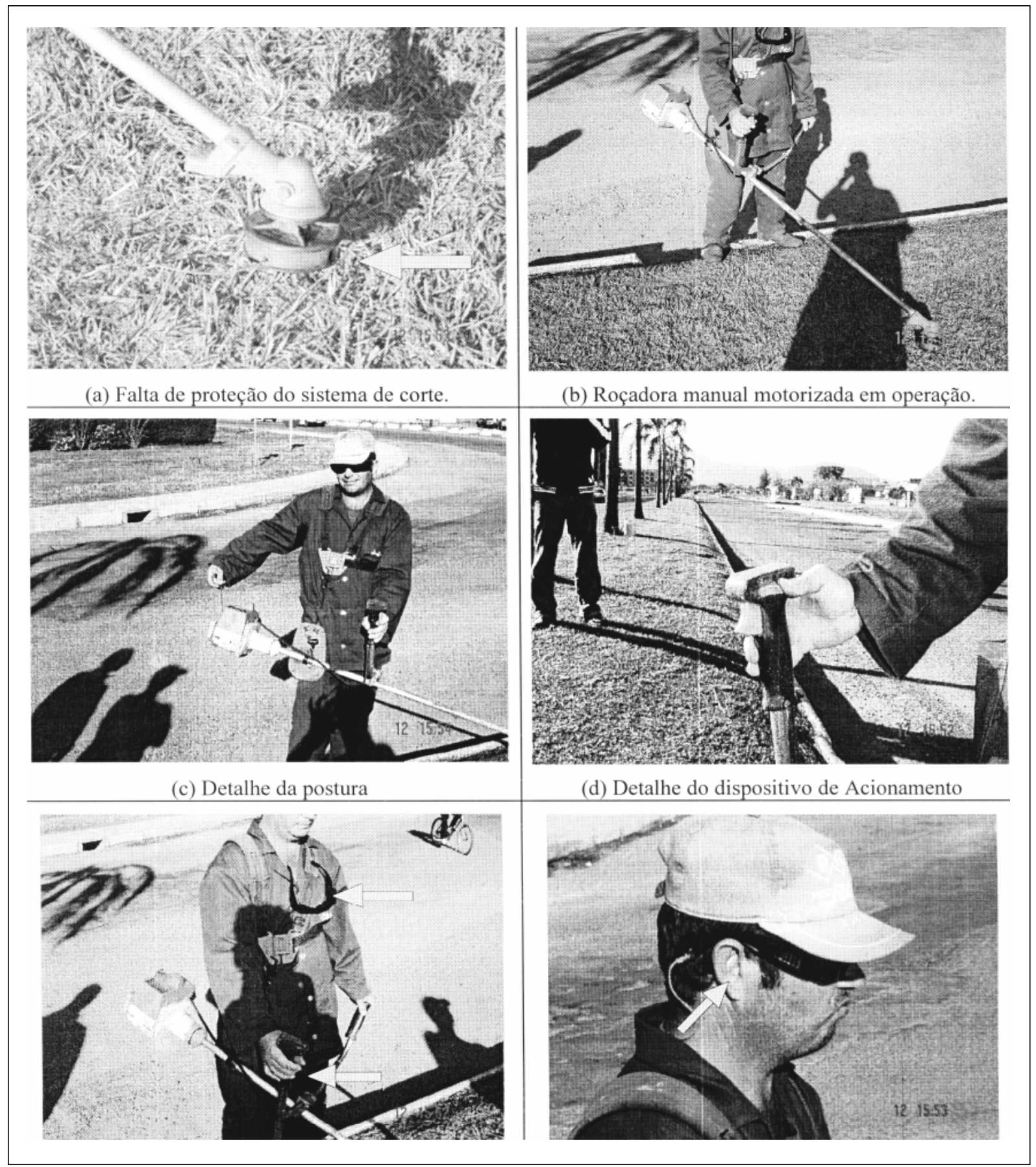

Figura 1 - Detalhes de "conformidades" e "não conformidades" encontradas no estudo.

que, segundo a NR 31 (2005), neste caso, “são de utilização obrigatória e devem, também obrigatoriamente, ser fornecidos pela empresa contratante". Neste trabalho, constatou-se que estes "EPIs" constituem-se em óculos de sol de vidro comum. Como se não bastasse o fato de o "EPI" ser totalmente inadequado em relação ao padrão exigido pela NR 31
(2005), com, por exemplo, estrutura reforçada de forma que o lançamento de objetos estranhos não provoquem sua quebra, o EPI em questão não é utilizado pelos operadores (Figura 1e). As luvas, também segundo relato, não são fornecidas pela empresa, constituindose os dois casos, portanto, em graves "não conformidades".

Ciência Rural, v.36, n.5, set-out, 2006. 
Segundo BRASIL (1994), “as máquinas deverão ser protegidas de maneira que a regulamentação e as normas nacionais de segurança e de higiene de trabalho sejam respeitadas”. Assim sendo, de acordo com esta lei, vinculada à NR 31 (2005) - que é uma norma nacional de segurança e higiene do trabalho -, em caso de acidentes, a empresa contratante poderá ser responsabilizada por danos à integridade física do operador, visto que o fornecimento de EPI, o treinamento para seu uso e a fiscalização para que o equipamento seja utilizado, são de sua total responsabilidade.

$\mathrm{Na}$ avaliação dos níveis de ruídos provocados pela roçadora durante o trabalho, foram realizadas medições com um decibelímetro manual, próximo ao ouvido do operador. Os níveis de ruído observados no ouvido esquerdo foram de 97,2 a 97,8 $\mathrm{dB}(\mathrm{A})$ e, no ouvido direito, de 102,5 a 103,2 dB(A). De acordo com o resultado obtido nas medições realizadas, o nível de ruído encontrado em operação foi bem acima do máximo permitido, o que, segundo a NR 15 (1990), deve ser abaixo de $85 \mathrm{~dB}$ (A) para um período de 8 horas de trabalho diárias. Portanto, seria necessária a utilização de protetores auriculares. Conforme pode ser observado na Figura $1 \mathrm{f}$, esse EPI não é utilizado pelos trabalhadores porque, segundo seu relato, não são fornecidos pela empresa contratante. Portanto, constata-se mais uma "não conformidade" e o flagrante desrespeito à lei pelo não cumprimento da NR31(2005).

O tempo de trabalho necessário para o consumo de todo o combustível do tanque da roçadora é de quarenta minutos, por este motivo, o operador faz pausas de vinte minutos; para reabastecer o equipamento, afiar as serras e resfriar o motor, cumprindo indiretamente as pausas no trabalho determinadas pela NR 15 (1990). Esta é uma "conformidade" diretamente relacionada com o projeto do equipamento.

Um aspecto que foi flagrado durante a execução do trabalho é a forma como os operadores são transportados da sede da empresa até o local onde desenvolvem suas atividades e vice-versa (Figura 2). Isto se opõe frontalmente à determinação de que "é vedado, em qualquer circunstância, o transporte de pessoas em máquinas e equipamentos motorizados e nos seus implementos acoplados” (NR 31, 2005).

De acordo com a análise desenvolvida, pode-se estabelecer as seguintes considerações finais: a utilização de estrutura protetora nas roçadoras deve sempre ser usada, diminuindo dessa forma o risco de acidentes graves e de possíveis questionamentos judiciais futuros. Além disso, sempre deve ser oferecido aos trabalhadores transporte adequado para o seu deslocamento até os locais de trabalho, a fim de evitar

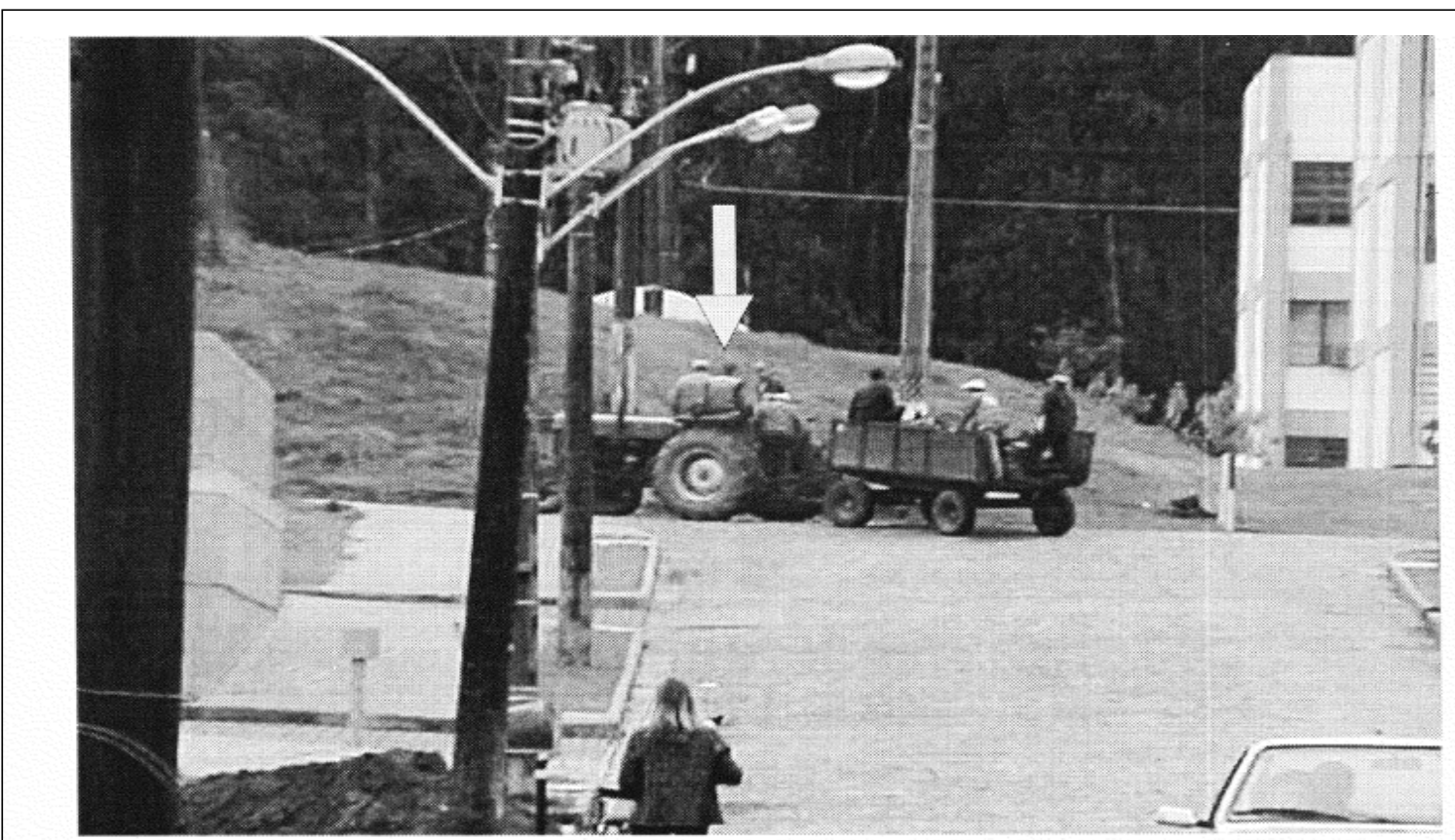

Forma de transporte dos funcionários da sede para o campo e vice-versa.

Figura 2 - "Não conformidades" graves identificadas no estudo. 
riscos a sua integridade física. Por fim, o fornecimento de equipamentos de proteção individual é indispensável para a segurança do operador durante o trabalho e deve-se orientar e treinar o trabalhador sobre o uso adequado de tais equipamentos, sob pena de questionamentos judiciais.

\section{REFERÊNCIAS}

ALONÇO, A. dos S. Metodologia de projeto para a concepção de máquinas agrícolas seguras. 2004. $221 \mathrm{f}$. Tese (Doutorado em Eng. Mecânica) - UFSC.

BRASIL. Decreto n.1255, de 29 de setembro de 1994. Promulga a Convenção n. 119 da Organização Internacional do Trabalho sobre Proteção das Máquinas, concluída em Genebra, em 25 de junho de 1963. Lex - Coletânea de legislação federal e marginália. São Paulo, v.58, p.1271-1277, jul/set, 1994.
NORMA Regulamentadora de Equipamento de Proteção Individual - NR 6: portaria $n^{\circ} 6$, de 19/08/1992. Capturado em 12 mai. 2005. Online. Disponível na Internet http:// www.tem.gov.br/temas/SegSau/Normas Regulamentadoras.

NORMA Regulamentadora de Atividades e Operações insalubres - NR 15 : de 23/11/1990. Capturado em 15 ago. 2004. Online. Disponível na Internet http://www.sobes.org.br/ nr17.htm.

NORMA Regulamentadora de Segurança e saúde no trabalho na Agricultura, Pecuária, Silvicultura, Exploração Florestal e Aqüicultura - NR 31: portaria n86, de 03/03/ 2005 - DOU de 04/03/2005. Capturado em 12 de mai. 2005. Online. Disponível na Internet http://www.tem.gov.br/temas/ SegSau/Normas Regulamentadoras.

VENTUROLI, F. et al. Avaliação do nível de ruído em marcenarias no Distrito Federal, Brasil. Revista Brasileira de Engenharia Agrícola e Ambiental, v.7, n.3, p.547-551, 2003. 